\title{
Role of physical activity in tumor patients and possible underlying mechanisms
}

\author{
Wilhelm Bloch • Eva Zopf • Philipp Zimmer • \\ Freerk T. Baumann
}

Received: 27 November 2012 / Accepted: 28 November 2012 /Published online: 8 January 2013

(C) European Group for Research into Elderly and Physical Activity (EGREPA) 2013

\begin{abstract}
A growing knowledge regarding the influence of exercise on adverse physiologic outcomes associated with cancer and its treatment exists. Aside from its effects on psychological behavior, quality of life, and cancer-related fatigue, physical exercise can target physical and cardiorespiratory fitness, insulin regulation and metabolic syndrome, body weight and composition, and immune function in tumor patients. The increasing number of study results for different cancer types, which prove the positive influences of physical activity in cancer patients, changed the contradictory opinions which existed until the end of the last century. Although an increasing number of studies showing the positive effects of physical activity and more specifically of endurance and resistance training in cancer patients have been published, the underlying mechanisms are mostly unknown. Thus, we summarized the current knowledge of the effects of physical activity and specific training in different tumor entities with specific respect to the possible underlying mechanisms. Especially, the association between physical activity and (1) the improvement of fatigue and the role of free radicals in this process, (2) the counterbalance of tumor-induced cachexia, (3) the improvement of the immune system for supportive tumor treatment, and (4) the possible role of epigenetic modulation against tumor and tumor treatment-dependent adverse physiologic outcomes is focused.
\end{abstract}

Keywords Resistance training · Endurance training . Epigenetic $\cdot$ Inflammation $\cdot$ Cachexia $\cdot$ Fatigue

\footnotetext{
W. Bloch $(\bowtie) \cdot$ E. Zopf $\cdot$ P. Zimmer $\cdot$ F. T. Baumann Department of Molecular and Cellular Sports Medicine, Institute of Cardiology and Sports Medicine,

German Sport University Cologne, Am Sportpark Müngersdorf 6, 50933 Cologne, Germany

e-mail: W.bloch@dshs-koeln.de
}

\section{Positive effects of physical activity in tumor patients}

The benefits of exercise on some of the adverse physiologic outcomes associated with cancer and its treatment, including physical and cardio-respiratory fitness, fatigue, insulin regulation and metabolic syndrome, body weight and composition, and immune function, were recently summarized in a review by Ingram and Visovsky [36]. These effects add to previously described and well-known effects of physical activity on psychological behavior, quality of life, and cancer-related fatigue in cancer patients $[6,41]$.

Until the 1990s, physical activities were often contraindicated for cancer patients. However, the increasing number of study results, which have proven the positive influence on the holistic situation of cancer patients, brought about a change $[32,73]$. In Germany, the first experiences with therapeutic exercise interventions in patients with neoplastic diseases date back over 30 years. In the summer of 1980, Prof. Schüle examined whether physical activity in patients with gynecological tumors is feasible - this was the first study nationwide. Based on his experience, the first cancer sports group was set up. This group pursued an improvement of mood, social interaction, and well-being [75].

By now, latest studies show the positive influence of differentiated endurance and resistance training programs in various cancer entities, however, with different levels of evidence. The national expert panels in North America, Australia, and Germany agree that physical activity in patients with oncological diseases is feasible, both during and after medical treatment. Exercise programs can improve physical fitness, muscular strength, and quality of life and have the potential to reduce fatigue. To date, these effects can be observed especially in patients with breast cancer, prostate cancer, and hemato-oncological diseases [8, 9, 32, 73].

In 1989, for possibly the first time, the influence of physical activity during chemotherapy was examined in 45 breast cancer 
patients. Patients that took part in the endurance training program on the bicycle showed a significant better physical performance compared to the control group [88]. Numerous studies were able to prove the holistic effects of endurance training during (high dose) chemotherapy [7, 42]. Recent studies with breast cancer patients show that resistance training can also be performed during chemotherapy without causing complications $[17,77]$. Patients can also exercise during radiotherapy and hormone therapy [39]. They benefit from an increase in muscle strength and lean body mass and a reduction of the fatigue syndrome. Further, exercise programs have positive effects on psychological and social parameters. A decrease in anxiety and an increase in quality of life can be observed $[1,58,73]$.

Physical exercise interventions in oncology pursue many specific aims that differ from the rehabilitation of other diseases. A targeted physical exercise program can, for example, positively influence the side effects of a prostate cancer treatment. A significant reduction of incontinence following a controlled exercise intervention has been demonstrated in several randomized studies [6, 59].

Whether resistance training, endurance training, or the combination of both has more effects on, for example, cancer-relevant biomarkers has rarely been investigated until today. The individual preference of the patient has to be taken into account when deciding on the method in order to improve quality of life [17]. Resistance training shows better physical effects in the field of muscle hypertrophy, while endurance training suggests better results in the field of endurance capacity $\left(\mathrm{VO}_{2} \max \right)$ [18]. Both types of training can help reduce fatigue symptoms [77].

Additionally, large epidemiological studies like the nurses' health study show a positive correlation between physical activity in breast cancer patients and the relapse and mortality rate of up to $40 \%$. The risk of relapse can be reduced through physical activity in colon cancer as well as in breast and prostate cancer [33, 40, 55].

\section{Improvement of fatigue by physical activity and the role of free radicals}

A major problem that $25-99 \%$ of all cancer patients experience during and/or after medical treatment is cancer-related fatigue (CRF). CRF has been identified as a multidimensional construct that involves a persistent physical, emotional, and/or cognitive tiredness or exhaustion that is not related to exertion level and is not relieved by rest or sleep. Therefore, a reduction of daily activities and motivation as well as a negative impact on quality of life and functional capacity can be observed [5, 12]. Mechanisms proposed as underlying cancer-related fatigue include 5-HT neurotransmitter dysregulation, vagal afferent activation, alterations in muscle and ATP metabolism, hypothalamic-pituitary-adrenal axis dysfunction, circadian rhythm disruption, and cytokine dysregulation. However, to date, the entire etiology of CRF is poorly understood, and the relative contributions of the neoplastic disease, various forms of cancer treatment, and comorbid conditions are widely unknown [67]. Especially, the involvement of oxidative stress as a general mechanism described to induce the fatigue syndrome is rarely evaluated in cancer patients, as well as its correlation to fatigue. Oxidative stress is described as an imbalance between reactive oxygen species (ROS) and the ability of antioxidant systems, both enzymatic and nonenzymatic, to neutralize them. Aside from a normal ROS production during aerobic metabolism, increased free radical levels potentially damage, for instance, cell membranes, proteins, and DNA and can be observed in pathophysiological conditions [78]. Further certain chemotherapeutic drugs (e.g., anthracycline) unfold their therapeutic effect by generating free radicals [20]. A principal involvement of oxidative and nitrosative stress in the development of chronic fatigue was recently described by Maes and Twisk [47] on the basis of a bio(psychosocial) model which describes the pathophysiology of chronic fatigue. Patients that experience chronic fatigue syndrome possess higher peroxide concentrations in their blood plasma [46]. When considering the points of clinical overlap (especially fatigue, immunological abnormalities) between patients with CRF and patients with chronic fatigue syndrome, similar observations can be expected in CRF patients [54]. In the long term, an increased oxidative stress level in the skeletal muscle is held to be responsible for a reduction in muscle mass and could therefore be associated with the physical and peripheral components of CRF [30]. On the other hand, an acute exerciseinduced increase of intracellular ROS can contribute to an improved muscle contraction due to an increased calcium release in the muscle and an improved ATP production [66, $69,85]$. Clearly, oxidative stress is necessary to a certain extent. In this context, the importance of the antioxidant defense systems needs to be considered.

The influence of physical activity on CRF has been well demonstrated in the meta-analyses by Cramp and Daniel [19] and Speck et al. [80]. Both were able to show that physical exercise is an effective intervention to counteract CRF. However, the influence of physical activity seems to depend on the cancer type, disease stage, and the time point of intervention. Even though a special, evidence-based physical activity program for CRF patients does not yet exist, both aerobic and resistance exercises show positive effects. Recent studies suggest that exercise interventions that are conducted in the aftercare show greater benefits than those administered during the medical treatment phase [53].

The influence of physical activity on oxidative stress, as a possible mediator of CRF, has hardly been studied in cancer patients. While intensive physical exercise is associated with an increased oxidative stress level, moderate physical exercise can decrease oxidative stress by improving the 
antioxidative capacity [3, 65]. Knop et al. [43] investigated whether a long hiking trip (over $500 \mathrm{~km}$ ) can influence oxidative stress and antioxidative capacity in breast cancer and prostate cancer patients. In the group of women who participated in a moderate 7-week hike, there was no significant change in ROS throughout the hike however a significant increase in antioxidative capacity. In the prostate cancer patients participating in the 5-week high-altitude hike, ROS concentration increased and the antioxidative capacity decreased initially. However, after a phase of regeneration, the ROS concentration decreased and the antioxidative capacity improved significantly. The study group therefore concludes that the antioxidative capacity of cancer patients can be positively influenced by long hiking trips [43]. An exercise-induced increase in endogenic, enzymatic antioxidants has proven to attenuate the side effects of certain cancer treatments $[32,79]$. Regarding CRF, a reduced oxidative stress level may play an important role in protecting skeletal muscle and therefore reducing CRF [79]. Yet, further studies are necessary to fully understand the etiology of CRF and the role of free radicals and physical exercise in this context. Presumably, physical activity does not only influence the physiologic and biologic components of CRF, but also has a psychological, social, and behavioral impact that indirectly influences fatigue outcomes.

\section{Counterbalance of tumor-induced cachexia through physical exercise}

Up to half of all cancer patients are affected by cancer cachexia, a syndrome defined by weight loss, asthenia, and anorexia [81]. The literature suggests that approximately $20 \%$ of all cancer deaths are related to cachexia rather than a direct tumor-related cause [84]. In general, cachexia is defined as the loss of muscle, with or without fat, and is frequently associated with anorexia, inflammation, and insulin resistance [2]. Since the major problem is the reduction of muscle mass, strategies are necessary to counterbalance the loss [83]. Until today, no specific interventions have proven to be effective in preventing or reversing the problem of cachexia. Besides pharmacological and nutritional therapies, exercise programs could help attenuate skeletal muscle wasting [62].

Only few studies have investigated the influence of physical activity on cachexia in cancer patients. Yet, these studies were able to show that resistance training leads to an increase in muscle strength and muscle mass. However, most of these studies involved breast and prostate cancer patients, who generally have a relatively low incidence of cachexia [17, 29, 73, 76]. The underlying mechanisms on the molecular level remain unclear.

Cachexia is strongly associated with chronically elevated serum levels of (pro)inflammatory cytokines, such as tumor necrosis factor $\alpha$ (TNF- $\alpha$ ), interleukin-6 (IL-6), and interferon$\gamma($ IFN- $\gamma)$ [25]. Animal studies could show that an injection of TNF- $\alpha$ leads to a loss of muscle and fat mass by activating the proteasomal degradation of proteins via the NFK pathway [67]. Further cachexia-reducing effects have been described for the injection of IFN- $\gamma$ and IL-6 antibodies [48, 90]. Interestingly, physical activity has the potential to reduce the proinflammatory environment. Petersen and Pedersen $[60,63]$ were able to demonstrate that exercise causes a strong short-term increase in IL-6, which ends up in a reduction of TNF- $\alpha$ and an increase in anti-inflammatory cytokines. It could be shown that endurance training as well as the substitution of erythropoietin downregulates chronic serum levels of IL-6 [14]. The authors assume that endurance training may prevent the development of cachexia however, on the contrary, may have negative effects on an existing cachexia. Beside the mentioned cytokines, the insulin-like growth factor 1 (IGF-1) seems to affect cancer cachexia in a positive manner [72, 74]. Schmidt et al. observed a lower reduction in muscle and body mass in those animals receiving IGF-1 injections [71]. Berg and Bang described exercise-induced IGF-1 elevations [11].

Another potential link between physical activity and a reduction in cachexia has been reported by Sandri et al., who described an exercise-induced increase of the transcriptional cofactor PGC- $1 \alpha$ [68]. PGC- $1 \alpha$ inhibits the transcription factor $\mathrm{FoxO}$, which promotes the expression of proteins making protein degradation. Additionally, it could be demonstrated that resistance training as well as endurance training inhibits muscle wasting by phosphorylating protein kinase B (Akt) and the transcription factor FoxO [87]. An elevated activity of the kinase mTOR, which is a key player in the production of muscle proteins, could only be observed in the resistance training group. The same animals showed an increase in the activity of satellite cells which was associated with elevated levels of the transcription factor MyoD. A resistance traininginduced activation of mTOR has also been reported [4, 28].

Further, patients may benefit from combined interventions. Penna et al. examined the influence of an omega-3 fatty acid substitution alone and in combination with an endurance exercise program in tumor-bearing mice [61]. Animals in the combined intervention group had a significant lower loss of muscle mass and strength. In order to define optimal exercise interventions for cachexia patients, it is important to analyze and understand the underlying mechanisms on the cellular level. Therefore, further randomized trials with homogeneous human samples and well-defined exercise programs are necessary.

\section{Effects of physical activity on the immune system-relevant aspects for supportive tumor treatment}

Today, it is not only suggested but also generally accepted that the immune system plays a role in reducing cancer risk 
by recognizing and eliminating abnormal cells or by means of acquired and/or innate components of the immune system [37]. The role of the immune system in endogenous cancer defense has also already been demonstrated. It is well known that the immune system initiates tumoricidal activities. Therefore, therapeutic strategies will be developed and used which are based on the therapeutic potential of the endogenous immune system [22]. Immune therapies play an increasing role in cancer treatment and are a novel approach in the treatment of systemic malignancies. Passive and adaptive immunotherapy has been applied in a wide variety of solid tumors such as malignant melanoma, renal cell carcinoma, and ovarian cancer [56]. When regarding the regulatory role of exercise for the immune system, moderate exercise seems to have a protective effect, whereas repeated bouts of strenuous exercise can result in immune dysfunction. Therefore, a potential role of exercise in endogenous tumor prevention and defense is suggested [27, 52]. Furthermore, immune function can be impaired by cancer treatment leading to an increased risk of inflammatory diseases. Recently, we were able to show the influence of physical activity on fever and pneumonia risk in leukemia and lymphoma patients during therapy-induced aplasia. We observed significant differences between the intervention and the control group in both the leukemia and the lymphoma patients [10]. These study results are in accordance with recent studies investigating immunological and hematological changes following high-dose chemotherapy. Three different studies show an improved or at least unchanged immune cell recovery in patients who had received highdose chemotherapy and exercised for 2 to 12 weeks. Especially, negative impacts on immune function could not be observed [23, 24, 31]. Also, in breast cancer survivors, exercise induces greater lymphocyte activation after a 6month exercise intervention [34]. Therefore, the question arises whether and to what extent physical activity or specific exercise interventions can influence the immune system in terms of preventing cancer, enhancing immune therapy, and avoiding treatment-related immune dysfunction and therefore inflammatory diseases.

In cancer prevention, the regulatory role of physical activity or rather specific exercise on pro- and antiinflammatory cytokines may be of major importance. Increased levels of proinflammatory factors, such as Creactive protein (CRP), IL-6, or TNF- $\alpha$, and decreased levels of anti-inflammatory factors, such as adiponectin, have been associated with an increased cancer risk. An association between chronic physical activity and lower levels of the inflammatory markers CRP, serum amyloid A, IL- 6 , and TNF- $\alpha$ in both men and women has been shown in some but not all exercise intervention studies [52]. Furthermore, an exercise-induced release of mainly anti-inflammatory cytokines by the skeletal muscle and an exercise-induced long-term alteration of cytokine release and receptor response are suggested [63]. In the wide range of cytokines influenced by exercise, the macrophage migration inhibitory factor (MIF) could be relevant for cancer defense. MIF regulates both the invasion of immune cells and the cancer cell migration in a contrary direction. While the immune cell invasion is inhibited and the natural killer (NK) cell activity is decreased by MIF, the tumor cell invasion is enhanced by MIF [44]. Recently, we were able to show that MIF is downregulated by a single bout of intensive exercise [70]. Further studies must show whether an exercise-induced alteration of cytokines, such as MIF, can influence the invasion of immune cells and tumor cells in a different direction and therefore contribute to defending against cancer.

On the cellular level, exercise-induced improvements in immune cell function can be found. The clinical significance of antiviral and anticancer defenses in NK cells, a heterogeneous population of lymphocytes, has been demonstrated $[13,21]$. In postmenopausal breast cancer survivors, physical exercise increased NK cell cytotoxicity and unstimulated $\left[{ }^{3} \mathrm{H}\right]$ thymidine uptake by peripheral blood lymphocytes, indicating an improved cellular immune defense by exercise [27]. When considering the suggested biological and therapeutic relevance of tumor defense, NK cells are an important first line of defense against tumor growth. Further, the important immunoregulatory properties of their CD56dim and CD56bright subsets mark them as candidates for immunotherapy for cancer. The redistribution of CD56dim and CD56bright cells in response to exercise may be a therapeutic benefit in children recovering from cancer; however, these speculations still remain undetermined. It has also been suggested that the stimulation of the CD56bright subset with the NK cell compartment may be a therapeutic effect to prevent relapse of a residual disease; exercise might be an excellent strategy to achieve this effect [82]. Distribution of immune cells seems to be of major importance for immune defense also against cancer. Exercise stress induces a substantial redistribution of $\mathrm{T}$ cells within lymphoid and nonlymphoid organs. It can be hypothesized that these stress-induced effects on lymphocyte trafficking might enhance immune surveillance and vigilance [45] and thus immune defense against cancer. Mechanisms leading to an altered immune cell migration across the vascular barrier could be involved. In lung cancer patients, 4-6 weeks of presurgical exercise training induced a systemic decrease of the intracellular adhesion molecule (ICAM)-1 in the blood. ICAM-1 is a cell surface glycoprotein that is upregulated in response to a variety of inflammatory mediators and is essential for controlling the migration of immune cells, cancer cell invasion, and metastasis. It plays a major role in lung tumorigenesis, and high systemic concentrations may serve as a useful indicator of advanced disease and 
are associated with poorer prognosis in lung cancer patients [38]. It can be speculated that an exercise-mediated change of cytokine profiles, surface molecule expressions, and subsequent alteration of immune cell distributions and also cancer cell invasions are of importance for tumor prevention and defense.

\section{Can epigenetic modulation due to physical activity be involved in resisting cancer?}

Epigenetic modulations are defined as covalent alterations of the chromatin which do not affect the DNA sequence. The most prominent epigenetic alterations are changes in DNA methylation and posttranslational modifications, like acetylation, methylation, phosphorylation, and sumoylation of histone proteins $[26,35]$. However, there is still a great lack of knowledge regarding the functions and interactions of epigenetic modulations. The mentioned epigenetic alterations can act as short- and long-term regulators of gene expression. Most tumor cells show abnormal epigenetic patterns. Until today, it remains unclear whether the dysregulation of epigenetic control is the effector or the result of neoplastic diseases [86]. Hypermethylation in promoter regions of tumor suppressor genes, for example, leads to gene silencing and a general DNA hypomethylation, which is associated with gene instability [89]. New promising pharmaceutical strategies, like histone deacetylase (HDAC) inhibitors, try to manipulate proteins which are involved in epigenetic modifications.

Interestingly, physical activity and nutrition can affect the epigenome in a similar manner. The duration of these effects vary from reversible short-term effects to long-lasting and generation-spanning effects. Nakajima et al. [57] described lower, age-dependent reductions of ASC gene methylation, which encodes for proinflammatory cytokines, in exercising individuals. Further, Zeng et al. [91] were able to show that exercise leads to the hypomethylation of a breast cancerspecific tumor supressor gene.

Besides the influence on DNA methylation patterns, physical activity has an immediate impact on HDACs and histone acetyltransferases [49, 50]. Until today, only few studies have investigated the influence of physical activity on these enzymes. McKinsey et al. [51] were able to show that HDAC class II enzymes are enriched in striated muscle cells. Knockout experiments of different class II HDACs lead to endothelial dysfunction and cardiac hypertrophy $[15,16]$. HDACs can be inactivated through phosphorylation, altered intracellular oxidative stress levels, and energy balances [51]. Physical activity does strongly affect all of these three factors.

Finally, Potthoff et al. [64] found elevated ubiquitindependent degradation levels of class II HDACs after an exercise intervention in mice. McGee and Hargreaves [50] were not able to verify these results in humans however found elevated levels of HDAC 5 ubiquitination immediately after a single bout of exercise.

In order to improve the knowledge of the impact of physical activity on epigenetic patterns, further studies are necessary. Aside from myocytes, these studies should also regard other tissues, for example, endothelial cells, progenitors, and circulating cells of the immune system. To obtain more detailed information on the impact of exercise on specific genes, it would be helpful to use techniques like ChIP assays and immunoprecipitation. The observed effects may help support pharmaceutical cancer treatments. Additionally, the properties of physical activity on the epigenetic level could be used to optimize preventive and rehabilitative exercise programs.

\section{Conclusion}

The growing evidence, regarding the beneficial effects of physical activity and moreover specific endurance and resistance training interventions for cancer patients during and after cancer treatment, lead to an implication of physical training as a supportive cancer treatment. Further knowledge about the involved mechanisms and the "dose response" must be given in order to exhaust the full potential of physical exercise in cancer patients.

Conflict of interest None.

\section{References}

1. Ahmed R, Thomas W, Yee D, Schmitt K (2006) Randomized controlled trial of weight training and lymphedema in breast cancer survivors. J Clin Oncol 24:2765-2772

2. Al-Majid S, Waters H (2008) The biological mechanisms of cancer-related skeletal muscle wasting: the role of progressive resistance exercise. Biol Res Nurs 10:7-20

3. Andersson H, Karlsen A, Blomhoff R, Raastad T, Kadi F (2010) Plasma antioxidant responses and oxidative stress following a soccer game in elite female players. Scand J Med Sci Sports 20:600-608

4. Baar K, Esser K (1999) Phosphorylation of p70S6k correlates with increased skeletal muscle mass following resistance exercise. Am J Physiol Cell Physiol 276:C120-C127

5. Barsevick A, Frost M, Zwinderman A, Hall P, Halyard M, GENEQOL Consortium (2010) I'm so tired: biological and genetic mechanisms of cancer-related fatigue. Qual Life Res 19:1419-1427

6. Baumann F, Zopf EM, Bloch W (2012) Clinical exercise interventions in prostate cancer patients - a systematic review of randomized controlled trials. Support Care Canc 20:212-233

7. Baumann FT, Kraut L, Schüle K, Bloch W, Fauser AA (2010) A controlled randomized study examining the effects of exercise therapy on patients undergoing haematopoietic stem cell transplantation. Bone Marrow Transplant 45:355-362

8. Baumann FT, Bernhörster M, Dimeo FC, Graf C, Jäger E, KleineTebbe A, Steindorf K, Tschuschke V (2009) Kommission „Krebs und Sport“ der Deutschen Krebsgesellschaft. Teil 1: Richtlinien für 
die Anwendung von Sport und körperlicher Aktivität in der Prävention, supportiven Therapie und Rehabilitation neoplastischer Erkrankungen. Forum-Das offizielle Magazin der Deutschen Krebsgesellschaft e.V. 4(24):14-17

9. Baumann FT, Bernhörster M, Dimeo FC, Graf C, Jäger E, KleineTebbe A, Steindorf K, Tschuschke V (2009) Kommission „Krebs und Sport" der Deutschen Krebsgesellschaft. Teil 2: Richtlinien für die Anwendung von Sport und körperlicher Aktivität in der Prävention, supportiven Therapie und Rehabilitation neoplastischer Erkrankungen. Forum-Das offizielle Magazin der Deutschen Krebsgesellschaft e.V. 5(24):9-12

10. Baumann FT, Zimmer P, Finkenberg K, Hallek M, Bloch W, Elter $\mathrm{T}$ (2012) Influence of endurance exercise on the risk of pneumonia and fever in leukemia and lymphoma patients undergoing high dose chemotherapy - a pilot study. J Sport Sci Med (in press)

11. Berg U, Bang P (2004) Exercise and circulating insulin-like growth factor I. Horm Res 62(Suppl 1):50-58

12. Berger AM, Barsevick AM, Cimprich B, Jacobsen PB, Ligibel JA, Murphy BA et al (2009) National Comprehensive Cancer Network (NCCN) clinical practice guidelines in oncology: cancer-related fatigue, V.I. 2009. National Comprehensive Cancer Network, Fort Washington

13. Brittenden J, Heys SD, Ross J, Eremin O (1996) Natural killer cells and cancer. Cancer 77:1226-1243

14. Carson JA, Baltgalvis KA (2010) Interleukin 6 as a key regulator of muscle mass during cachexia. Exerc Sport Sci Rev 38:168-176

15. Chang S, McKinsey TA, Zhang CL, Richardson JA, Hill JA, Olson EN (2004) Histone deacetylases 5 and 9 govern responsiveness of the heart to a subset of stress signals and play redundant roles in heart development. Mol Cell Biol 24:8467-8476

16. Chang S, Young BD, Li S, Qi X, Richardson JA, Olson EN (2006) Histone deacetylase 7 maintains vascular integrity by repressing matrix metalloproteinase 10. Cell 126:321-334

17. Courneya K, Segal R, Mackey J et al (2007) Effects of aerobic and resistance exercise in breast cancer patients receiving adjuvant chemotherapy: a multicenter randomized controlled trial. J Clin Oncol 25:4396-4404

18. Courneya KS, McKenzie DC, Mackey JR et al (2008) Moderators of the effects of exercise training in breast cancer patients receiving chemotherapy: a randomized controlled trial. Cancer 112:1845-1853

19. Cramp F, Daniel J (2008) Exercise for the management of cancerrelated fatigue in adults. Cochrane Database Syst Rev 16(2): CD006145

20. D'Andrea MD (2005) Use of antioxidants during chemotherapy and radiotherapy should be avoided. Canc J Clinic 55:319-321

21. Demaria S, Volm MD, Shapiro RL, Yee HT, Oratz R, Formenti SC, Muggia F, Symmans WF (2001) Development of tumor-infiltrating lymphocytes in breast cancer after neoadjuvant paclitaxel chemotherapy. Clin Cancer Res 7:3025-3030

22. Dimberu PM, Leonhardt RM (2011) Cancer immunotherapy takes a multi-faceted approach to kick the immune system into gear. Yale J Biol Med 84:371-380

23. Dimeo F, Fetscher S, Lange W, Mertelsmann R, Keul J (1997) Effects of aerobic exercise on the physical performance and incidence of treatment-related complications after high-dose chemotherapy. Blood 90:3390-3394

24. Dimeo FC, Tilmann MH, Bertz H, Kanz L, Mertelsmann R, Keul J (1997) Aerobic exercise in the rehabilitation of cancer patients after high dose chemotherapy and autologous peripheral stem cell transplantation. Cancer 79:1717-1722

25. Donohoe CL, Ryan AM, Reynolds JV (2011) Cancer cachexia: mechanisms and clinical implications. Gastroenterol Res Pract 2011:601434

26. Dulac C (2010) Brain function and chromatin plasticity. Nature 465:728-735

27. Fairey AS, Courneya KS, Field CJ, Bell GJ, Jones LW, Mackey JR (2005) Randomized controlled trial of exercise and blood immune function in postmenopausal breast cancer survivors. J Appl Physiol 98:1534-1540

28. Fujita S, Abe T, Drummond MJ, Cadenas JG, Dreyer HC, Sato Y, Volpi E, Rasmussen BB (2007) Blood flow restriction during lowintensity resistance exercise increases $\mathrm{S} 6 \mathrm{~K} 1$ phosphorylation and muscle protein synthesis. J Appl Physiol 103:903-910

29. Galvao DA, Nosaka K, Taaffe DR, Spry N, Kristjanson LJ, McGuigan MR, Suzuki K, Yamaya K, Newton RU (2006) Resistance training and reduction of treatment side effects in prostate cancer patients. Med Sci Sports Exerc 38:2045-2052

30. Gilliam LA, St Clair DK (2011) Chemotherapy-induced weakness and fatigue in skeletal muscle: the role of oxidative stress. Antioxid Redox Signal 15(9):2543-2563

31. Hayes S, Davies PS, Parker T, Bashford J (2003) Total energy expenditure and body composition changes following peripheral blood stem cell transplantation and participation in an exercise programme. Bone Marrow Transplant 31:331-338

32. Hayes S, Spence R, Galvao D, Newton R (2009) Australian Association for Exercise and Sport Science position stand: optimising cancer outcomes through exercise. J Sci Med Sport/Sport Med Aust 12:428-434

33. Holmes MD, Chen WY, Feskanich D, Kroenke CH, Colditz GA (2005) Physical activity and survival after breast cancer diagnosis. JAMA 293:2479-2486

34. Hutnick NA, Williams NI, Kraemer WJ, Orsega-Smith E, Dixon RH, Bleznak AD, Mastro AM (2005) Exercise and lymphocyte activation following chemotherapy for breast cancer. Med Sci Sports Exerc 37:1827-1835

35. Ikegami K, Ohgane J, Tanaka S, Yagi S, Shiota K (2009) Interplay between DNA methylation, histone modification and chromatin remodeling in stem cells and during development. Int J Dev Biol $53: 203-214$

36. Ingram C, Visovsky C (2007) Exercise intervention to modify physiologic risk factors in cancer survivors. Semin Oncol Nurs 23:275-284

37. Jakóbisiak M, Lasek W, Gołab J (2004) Natural mechanisms protecting against cancer. Immunol Lett 90:103-122

38. Jones LW, Eves ND, Peddle CJ, Courneya KS, Haykowsky M, Kumar V, Winton TW, Reiman T (2009) Effects of presurgical exercise training on systemic inflammatory markers among patients with malignant lung lesions. J Appl Physiol Nutr Metab 34:197-202

39. Kapur G, Windsor PM, McCowan C (2010) The effect of aerobic exercise on treatment-related acute toxicity in men receiving radical external beam radiotherapy for localised prostate cancer. European J Canc Care 19:643-647

40. Kenfield SA, Stampfer MJ, Giovannucci E, Chan JM (2011) Physical activity and survival after prostate cancer diagnosis in the health professionals follow-up study. J Clin Oncol 29:726-732

41. Knobf MT, Musanti R, Dorward J (2007) Exercise and quality of life outcomes in patients with cancer. Semin Oncol Nurs 23:285-296

42. Knols R, Aaronson NK, Uebelhart D, Fransen J, Aufdemkampe G (2005) Physical exercise in cancer patients during and after medical treatment: a systematic review of randomized and controlled clinical trials. J Clin Oncol 23:3830-3842

43. Knop K, Schwan R, Bongartz M, Bloch W, Brixius K, Baumann F (2011) Sport and oxidative stress in oncological patients. Int $\mathrm{J}$ Sports Med 32:960-964

44. Krockenberger M, Dombrowski Y, Weidler C, Ossadnik M, Hönig A, Häusler S, Voigt H, Becker JC, Leng L, Steinle A, Weller M, Bucala R, Dietl J, Wischhusen J (2008) Macrophage migration inhibitory factor contributes to the immune escape of ovarian cancer by down-regulating NKG2D. J Immunol 180:7338-7348

45. Krüger K, Mooren FC (2007) T cell homing and exercise. Exerc Immunol Rev 13:37-54

46. Maes M, Kubera M, Uytterhoeven $M$ et al (2011) Increased plasma peroxides as a marker of oxidative stress in myalgic 
encephalomyelitis/chronic fatigue syndrome (ME/CFS). Med Sci Monit 17:SC11-SC15

47. Maes M, Twisk FN (2010) Chronic fatigue syndrome: Harvey and Wessely's (bio)psychosocial model versus a bio(psychosocial) model based on inflammatory and oxidative and nitrosative stress pathways. BMC Med 8:35

48. Matthys P, Heremans H, Opdenakker G, Billiau A (1991) Antiinterferon-gamma antibody treatment, growth of Lewis lung tumours in mice and tumour-associated cachexia. Eur J Cancer $27: 182-187$

49. McGee SL, Fairlie E, Garnham AP, Hargreaves M (2009) Exercise-induced histone modifications in human skeletal muscle. J Physiol 587:5951-5958

50. McGee SL, Hargreaves M (2011) Histone modifications and exercise adaptations. J Appl Physiol 110:258-263

51. McKinsey TA, Zhang CL, Lu J, Olson EN (2000) Signaldependent nuclear export of a histone deacetylase regulates muscle differentiation. Nature 408(6808):106-111

52. McTiernan A (2008) Mechanisms linking physical activity with cancer. Nat Rev Cancer 8:205-211

53. McNeely ML, Courneya KS (2010) Exercise programs for cancerrelated fatigue: evidence and clinical guidelines. J National Comprehen Canc Network 8(8):945-953

54. Meeus M, Mistiaen W, Lambrecht L, Nijs J (2009) Immunological similarities between cancer and chronic fatigue syndrome: the common link to fatigue? Anticancer Res 29:4717-4726

55. Meyerhardt JA, Giovannucci EL, Holmes MD, Chan AT, Chan JA, Colditz GA, Fuchs CS (2006) Physical activity and survival after colorectal cancer diagnosis. J Clin Oncol 24:3527-3534

56. Murala S, Alli V, Kreisel D, Gelman AE, Krupnick AS (2010) Current status of immunotherapy for the treatment of lung cancer. J Thorac Dis 2:237-244

57. Nakajima K, Takeoka M, Mori M, Hashimoto S, Sakurai A, Nose H, Higuchi K, Itano N, Shiohara M, Oh T, Taniguchi S (2010) Exercise effects on methylation of ASC gene. Int J Sports Med 31:671-675

58. Ohira T, Schmitz KH, Ahmed RL, Yee D (2006) Effects of weight training on quality of life in recent breast cancer survivors: the weight training for breast cancer survivors study. Cancer 106:2076-2083

59. Overgard M, Angelsen A, Lydersen S, Morkved S (2008) Does physiotherapist-guided pelvic floor muscle training reduce urinary incontinence after radical prostatectomy? A randomised controlled trial. Eur Urol 54:438-448

60. Pedersen BK, Febbraio MA (2008) Muscle as an endocrine organ: focus on muscle-derived interleukin-6. Physiol Rev 88:1379-1406

61. Penna F, Busquets S, Pin F, Toledo M, Baccino FM, LópezSoriano FJ, Costelli P, Argilés JM (2011) Combined approach to counteract experimental cancer cachexia: eicosapentaenoic acid and training exercise. J Cachex Sarcopenia Muscle 2:95-104

62. Perniconi B (2008) A meta-analysis on a therapeutic dilemma: to exercise or not to exercise in cachexia. Basic Appl Myol 18:105-120

63. Petersen AM, Pedersen BK (2005) The anti-inflammatory effect of exercise. J Appl Physiol 98:1154-1162

64. Potthoff MJ, Wu H, Arnold MA, Shelton JM, Backs J, McAnally J, Richardson JA, Bassel-Duby R, Olson EN (2007) Histone deacetylase degradation and MEF2 activation promote the formation of slow-twitch myofibers. J Clin Invest 117:2459-2467

65. Radak Z, Chung HY, Goto S (2008) Systemic adaptation to oxidative challenge induced by regular exercise. Free Radic Biol Med 44:153-159

66. Reid MB, Khawli FA, Moody MR (1993) Reactive oxygen in skeletal muscle. III. Contractility of unfatigued muscle. J Appl Physiol 75:1081-1087

67. Ryan JL, Carroll JK, Ryan EP, Mustian KM, Fiscella K, Morrow GR (2007) Mechanisms of cancer-related fatigue. Oncologist 12:22-34
68. Sandri M, Lin J, Handschin C, Yang W, Arany ZP, Lecker SH, Goldberg AL, Spiegelman BM (2006) PGC-1alpha protects skeletal muscle from atrophy by suppressing FoxO3 action and atrophy-specific gene transcription. Proc Natl Acad Sci U S A 103:16260-16265

69. Sandström ME, Zhang SJ, Bruton J, Silva JP, Reid MB, Westerblad H, Katz A (2006) Role of reactive oxygen species in contractionmediated glucose transport in mouse skeletal muscle. J Physiol 575:251-262

70. Schmidt A, Bierwirth S, Weber S, Platen P, Schinköthe T, Bloch W (2009) Short intensive exercise increases the migratory activity of mesenchymal stem cells. Br J Sports Med 43:195-198

71. Schmidt K, von Haehling S, Doehner W, Palus S, Anker SD, Springer J (2011) IGF-1 treatment reduces weight loss and improves outcome in a rat model of cancer cachexia. J Cachex Sarcopenia Muscle 2:105-109

72. Schmitz KH, Ahmed RL, Hannan PJ, Yee D (2005) Safety and efficacy of weight training in recent breast cancer survivors to alter body composition, insulin, and insulin-like growth factor axis proteins. Canc Epidemiol Biomark Prev $14: 1672-1680$

73. Schmitz KH, Courneya KS, Matthews C, Demark-Wahnefried W, Galvão DA, Pinto BM, Irwin ML, Wolin KY, Segal RJ, Lucia A, Schneider CM, von Gruenigen VE, Schwartz AL (2010) American College of Sports Medicine roundtable on exercise guidelines for cancer survivors. Med Sci Sports Exer 42:1409-1426

74. Schmitz K, Ahmed R, Hannan P, Yee D (2005) Safety and efficacy of weight training in recent breast cancer survivors to alter body composition, insulin and insulin-like growth factor axis proteins. Canc Epidemiol Biomarker Prev 14:1672-1680

75. Schüle K (1983) Zum Stellenwert der Sport und Bewegungstherapie bei Patientinnen mit Brust- oder Unterleibskrebs. Rehabilitation 22:36-39

76. Segal RJ, Reid RD, Courneya KS, Malone SC, Parliament MB, Scott CG, Venner PM, Quinney HA, Jones LW, Slovinec D'Angelo ME, Wells GA (2003) Resistance exercise in men receiving androgen deprivation therapy for prostate cancer. J Clin Oncol 21:1653-1659

77. Segal RJ, Reid RD, Courneya RJ, Sigal GP, Kenny DG, PrudHomme DG et al (2009) Randomized controlled trial of resistance or aerobic exercise in men receiving radiation for prostate cancer. $\mathrm{J}$ Clin Oncol 27:344-351

78. Sies H (1997) Oxidative stress: oxidants and antioxidants. Exp Physiol 82:291-295

79. Simone CB 2nd, Simone NL, Simone V, Simone CB (2007) Antioxidants and other nutrients do not interfere with chemotherapy or radiation therapy and can increase kill and increase survival, part 1. Altern Ther Health Med 13:22-28

80. Speck RM, Courneya KS, Mâsse LC et al (2010) An update of controlled physical activity trials in cancer survivors: a systematic review and meta-analysis. J Canc Surviv 4(2):87-100

81. Stephens NA, Gallagher IJ, Rooyackers O, Skipworth RJ, Tan BH, Marstrand T, Ross JA, Guttridge DC, Lundell L, Fearon KC, Timmons JA (2010) Using transcriptomics to identify and validate novel biomarkers of human skeletal muscle cancer cachexia. Genome Med 2:1

82. Timmons BW, Cieslak T (2008) Human natural killer cell subsets and acute exercise: a brief review. Exerc Immunol Rev 14:8-23

83. Tisdale MJ (2002) Cachexia in cancer patients. Nat Rev Cancer 2:862-871

84. Tisdale MJ (2008) Catabolic mediators of cancer cachexia. Curr Opin Support Palliat Care 2:256-261

85. Toyoda T, Tanaka S, Ebihara K, Masuzaki H, Hosoda K (2006) Low-intensity contraction activates the alpha1-isoform of 5'-AMPactivated protein kinase in rat skeletal muscle. Am J Physiol 290:583-590 
86. Tsai HC, Baylin SB (2011) Cancer epigenetics: linking basic biology to clinical medicine. Cell Res 21:502-517

87. Wang XH, Du J, Klein JD, Bailey JL, Mitch WE (2009) Exercise ameliorates chronic kidney disease-induced defects in muscle protein metabolism and progenitor cell function. Kidney Int 76:751759

88. Winningham ML, MacVicar MG, Bondoc M, Anderson JI, Minton JP (1989) Effect of aerobic exercise on body weight and composition in patients with breast cancer on adjuvant chemotherapy. Oncol Nurs For 16:683-689
89. Wong NC, Craig JM (eds) (2011) Epigenetics: a reference manual. Caister Academic, Norfolk

90. Zaki MH, Nemeth JA, Trikha M (2004) CNTO 328, a monoclonal antibody to IL-6, inhibits human tumor-induced cachexia in nude mice. Int J Cancer 111:592-595

91. Zeng H, Irwin ML, Lu L, Risch H, Mayne S, Mu L, Deng Q, Scarampi L, Mitidieri M, Katsaros D, Yu H (2011) Physical activity and breast cancer survival: an epigenetic link through reduced methylation of a tumor suppressor gene L3MBTL1. Breast Canc Res Treat 133(1):127-135 